\title{
Ultrasonic Evaluation of Welding Residual Stresses in Stainless Steel Pressure Vessel
}

Yashar Javadi

Ph.D. Candidate, Department of Mechanical Engineering, Amirkabir University of Technology, 424 Hafez Ave., Tehran, Iran.

(Corresponding author's e-mail: yashar_javadi@aut.ac.ir; Tel: +98 9124402303, Fax: +98 216641 9736.)

Hamed Salimi Pirzaman

MSc. Student, Department of Mechanical Engineering, Amirkabir University of Technology, 424 Hafez Ave., Tehran, Iran. hamedsalimi66@gmail.com

Mohammadreza Hadizadeh Raeisi

BSc. Student, Department of Mechanical Engineering, Amirkabir University of Technology, 424 Hafez Ave., Tehran, Iran. m.r.hadizadeh.r@gmail.com

Mehdi Ahmadi Najafabadi

Associate Professor, Department of Mechanical Engineering, Amirkabir University of Technology, 424 Hafez Ave., Tehran, Iran.

ahmadin@aut.ac.ir

Abstract

This paper investigates ultrasonic method in stress measurement of a pressure vessel made of austenitic stainless steel 304L. Longitudinal critically refracted $\left(L_{C R}\right)$ waves are employed to measure the welding residual stresses. The acoustoelastic constant is measured through a hydro test while the pressure vessel is kept intact. Hole-drilling method is used to verify the results of ultrasonic measurement corresponding to axial and hoop residual stresses of the pressure vessel. The results show good agreement between hole-drilling and ultrasonic stress measurements which is accomplished nondestructively.

Keywords: Pressure Vessel; Ultrasonic; Nondestructive Stress Measurement; $L_{C R}$ waves; Acoustoelastic Constant.

\section{1- INTRODUCTION}

The engineering properties of the structural components, particularly fatigue life, deformation, dimensional stability, corrosion resistance, and brittle fracture can be significantly influenced by residual stresses. Residual stresses can be defined as the stresses that remain within a material after manufacturing, in the absence of external loads or thermal gradients. Welding is an essential production process in the industry which generates residual stresses at a notable level. The welding residual stresses are formed in the structure as the result of differential contractions which occur during the weld solidification and cooling to the room temperature. Ultrasonic method, known also as longitudinal critically refracted $\left(L_{C R}\right)$ wave techniques, is not limited by the material type and can be employed for stresses measurements on thick 
samples. The technique is based on the acoustoelastic effect, according to which the velocity of elastic wave propagated in solids depend on the mechanical stress.

Ultrasonic stress evaluation was discussed by Thompson, et al. [1] and Schneider [2]. Applications of the $L_{C R}$ technique were given in a number of studies, remarkably Santos and Bray [3, 4] and Bray and Chance [5]. Tanala et al. [6] explained a combination of subsurface longitudinal and Rayleigh waves to determine the welding stresses near surface. Employing the subsurface longitudinal waves in rail stress measurement has been studied by Szelazek [7].

Pressure vessels, piping and tanks are important engineering equipments which contain various types of fluids at the range of temperatures and pressures. Residual stresses were ultrasonically measured in a pressure vessel by Bray [8]. He constructed a pressure vessel from A106 carbon steel to demonstrate the $L_{C R}$ ultrasonic technique for indicating changes in wall and weld stress. However, he did not completely measure the hoop and axial residual stresses of the pressure vessel. Since stainless steel pressure vessels are widely utilized in the industry, the residual stress measurement of a pressure vessel constructed from $304 \mathrm{~L}$ stainless steel is investigated in this study. The ultrasonic measurements are verified with the values of stresses measured by hole-drilling method.

\section{2- THEORETICAL BACKGROUND}

Different ultrasonic configurations can be utilized for residual stresses measurements by $L_{C R}$ waves. Generally, waves are launched by a transmitter transducer, propagate through a region of the material, and are detected by a receiver transducer, as shown in Fig. 1. The residual stress in a subsurface layer is determined while the depth of layer is related to the ultrasonic wave-length, often exceeding a few millimetres.

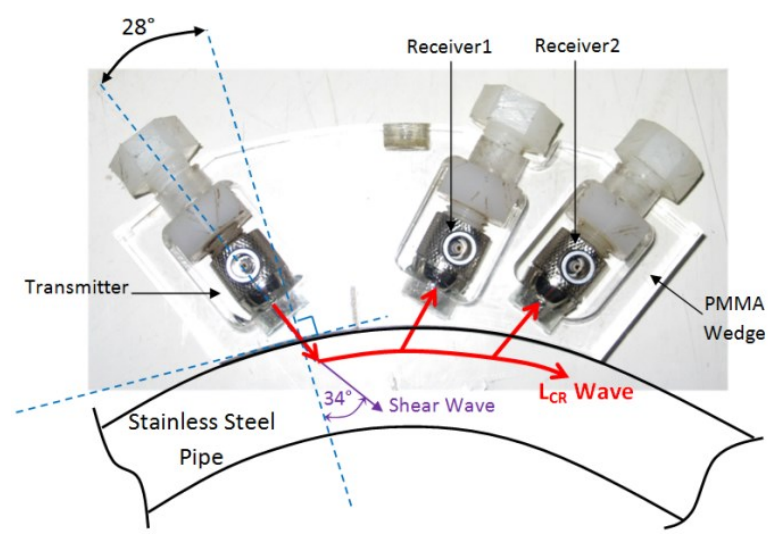

Fig. 1. $L_{C R}$ Wave Propagated in the Stainless Steel Pipe through the PMMA Wedge

The relation between measured travel-time change of $L_{C R}$ wave and the corresponding uniaxial stress is derived by Egle and Bray [9] to be:

$$
\Delta \sigma=\frac{E}{L t_{0}}\left(t-t_{0}-\Delta t_{T}\right)
$$

where $\Delta \sigma$ is stress change, $E$ is the elastic modulus and $L$ is the acoustoelastic constant for longitudinal waves propagating in the direction of the applied stress field. Also, $t$ is the experimental travel-time which would be measured on the welded structure that is being evaluated; $t_{0}$ is travel-time for a homogeneous, isotropic, stress-free sample at the room temperature and $\Delta t_{T}$ is temperature difference effect between the measurement temperature and room temperature on the travel-time. With knowledge of the weld induced change in travel-time and the measured acoustoelastic constant, the stress change produced by the weld may be calculated.

\section{3- EXPERIMENTAL PROCEDURES}

\section{3-1. Sample Description}

A pressure vessel is constructed from two $304 \mathrm{~L}$ stainless steel pipe and two standard caps while the diameter and thickness is equal to 5 inch and $6 \mathrm{~mm}$ respectively (Fig. 2). The pipes and caps are stress relieved at $450^{\circ} \mathrm{C}$ for 6 hours, before being employed in manufacturing process of pressure vessel. The welding processes include a main weld to join the pipes, 
welding process of right cap, left cap weld and nozzle welding according to the specifications mentioned in Table 1. The welding processes are semi-automated tungsten inert gas (TIG) welding except the nozzle which is welded manually. The pipes and caps are welded in V-groove ( $60^{\circ}$ included angle) while root gap is equal to $2 \mathrm{~mm}$ and $308 \mathrm{~L}$ is selected as the filler material. All of the weld reinforcements are removed by $30000 \mathrm{rpm}$ hand grinder to facilitate ultrasonic measurements. However, temperature during the grinding process is kept less than $50^{\circ} \mathrm{C}$ to prevent generation of thermal stresses. The residual stresses are measured by the ultrasonic and hole-drilling method with the characterizations shown in Fig. 2.

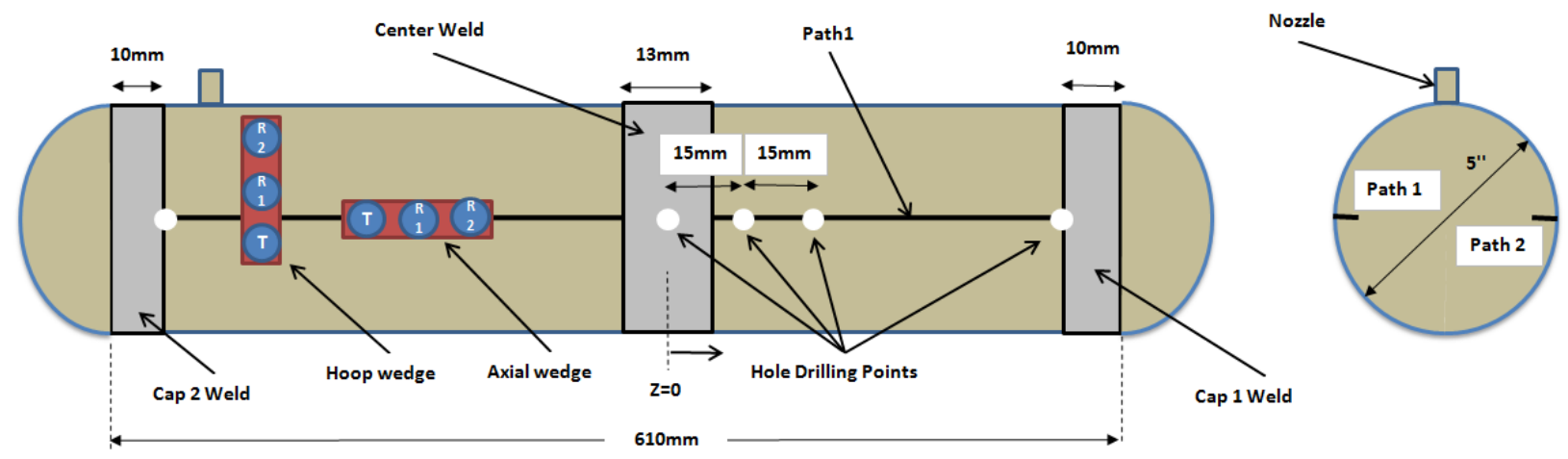

Fig. 2. Pressure Vessel Dimensions

Table 1: Welding specifications of Pressure Vessel

\begin{tabular}{|c|c|c|c|c|c|}
\hline & & $\begin{array}{l}\text { Welding } \\
\text { Sequence } \\
\text { (Degree) }\end{array}$ & $\begin{array}{l}\text { Welding } \\
\text { Current }(A)\end{array}$ & $\begin{array}{l}\text { Welding } \\
\text { Voltage (V) }\end{array}$ & $\begin{array}{l}\text { Welding Speed } \\
(\mathrm{mm} / \mathrm{s})\end{array}$ \\
\hline \multirow{6}{*}{$\begin{array}{l}\text { Main Weld } \\
\text { (Pipe-Pipe) }\end{array}$} & \multirow{2}{*}{ First Pass } & $0-180$ & 130 & $12-13$ & 1.3 \\
\hline & & $180-360$ & 130 & $12-13$ & 1.46 \\
\hline & \multirow{2}{*}{$\begin{array}{l}\text { Second } \\
\text { Pass }\end{array}$} & $0-180$ & 130 & $12-13$ & 0.75 \\
\hline & & $180-360$ & 130 & $12-13$ & 0.73 \\
\hline & \multirow{2}{*}{$\begin{array}{l}\text { Third } \\
\text { Pass }\end{array}$} & $0-180$ & 130 & $12-13$ & 0.84 \\
\hline & & $180-360$ & 130 & $12-13$ & 0.91 \\
\hline \multirow{6}{*}{$\begin{array}{l}\text { Cap1 Weld } \\
\text { (Right Cap-Pipe) }\end{array}$} & \multirow{2}{*}{ First Pass } & $45-225$ & 100 & $8-9$ & 1.30 \\
\hline & & $225-405$ & 100 & $8-9$ & 1.35 \\
\hline & \multirow{2}{*}{$\begin{array}{l}\text { Second } \\
\text { Pass }\end{array}$} & $45-225$ & 100 & $8-9$ & 0.69 \\
\hline & & $225-405$ & 100 & $8-9$ & 1.00 \\
\hline & \multirow{2}{*}{$\begin{array}{l}\text { Third } \\
\text { Pass }\end{array}$} & $45-225$ & 100 & $8-9$ & 0.47 \\
\hline & & $225-405$ & 100 & $8-9$ & 0.64 \\
\hline \multirow{5}{*}{$\begin{array}{l}\text { Cap2 Weld } \\
\text { (Left Cap-Pipe) }\end{array}$} & \multirow{2}{*}{ First Pass } & $45-225$ & 160 & $14-14.5$ & 0.74 \\
\hline & & $225-405$ & 160 & $13.5-14.5$ & 0.8 \\
\hline & \multirow{2}{*}{$\begin{array}{l}\text { Second } \\
\text { Pass }\end{array}$} & $45-225$ & 160 & $10.5-11.5$ & 0.71 \\
\hline & & $225-405$ & 160 & $10.5-11.5$ & 1.00 \\
\hline & Third & $45-225$ & 160 & $11.5-12.5$ & 0.83 \\
\hline
\end{tabular}




\begin{tabular}{lllccc}
\hline & Pass & $225-405$ & 160 & $12.5-13.5$ & 0.8 \\
\hline Nozzle & $\begin{array}{l}\text { Single } \\
\text { Pass }\end{array}$ & $0-360$ & 120 & $10.5-11.5$ & 3.10 \\
\hline
\end{tabular}

\section{3-2. Measurement device}

The measurement device, shown in Fig. 3, includes an ultrasonic box, computer and time of flight (TOF) measuring element. The ultrasonic box is a $100 \mathrm{MHz}$ ultrasonic testing device which has synchronization between the pulser signal and the internal clock, which controls the $A / D$ converter. This allows very precise measurements of the time of flight better than $1 \mathrm{~ns}$, however a MATLAB subroutine is employed to increase the resolution to $0.1 \mathrm{~ns}$. TOF measuring element includes three normal transducers assembled on an integrated wedge to measure the time of flight. A poly methyl methacrylate (PMMA) material, under the trademark Plexiglas, is cut by laser to construct the wedge. The TOF is measured on two paths (path1\&2 in Fig. 2) by two different types of wedges needed to measure hoop and axial stress separately. Surface curvature of pipe is taken into account in laser cutting of the bottom surface in both of the wedges. A three-probe arrangement is utilized, with one sender and two receivers in order to eliminate the effects of environment temperature on the travel time. Three normal transducers with the same frequency are used where their nominal frequencies are 5 $\mathrm{MHz}$ and the diameter of the piezoelectric elements is $6 \mathrm{~mm}$. The pressure needed to keep the couplant film constant, is provided by a screw while a load cell is employed for load adjustment. Furthermore, a thermocouple and thermometer are utilized to record the environmental temperature change for compensation its effect on the TOF. The scanning paths start from melted zone (MZ) of the right cap, pass the main center weld and end to $M Z$ of the left cap. Moving step is equal to 2 $\mathrm{mm}$ for the points near and on the MZ while it is increased to $10 \mathrm{~mm}$ far away the weld. The TOF is measured three times for each point and the average data is calculated.
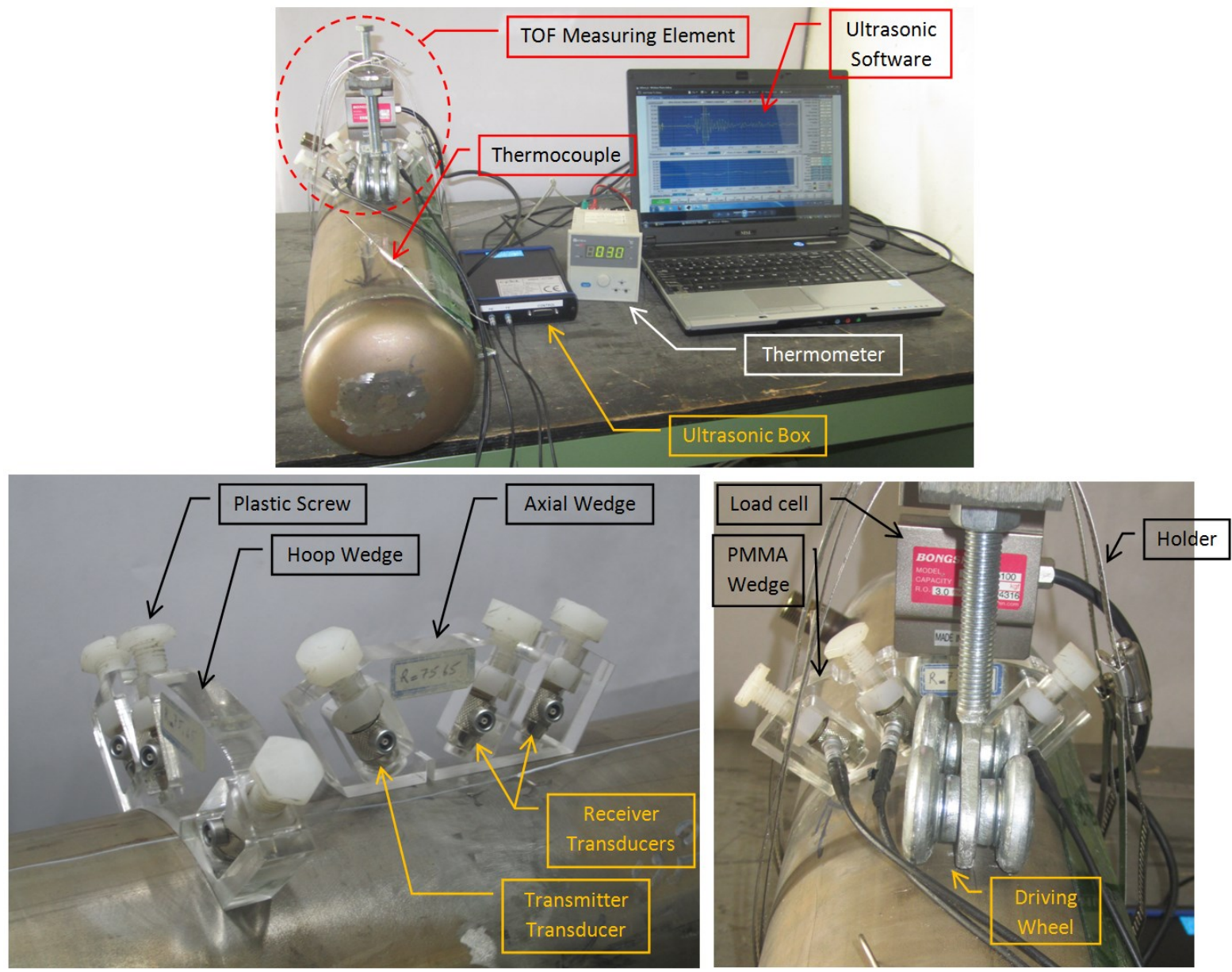

Fig. 3. Measurement Devices for TOF measurement 


\section{3-3. Determination of $L_{C R}$ Penetration Depth}

When the $L_{C R}$ technique is applied to an application with limited wall thickness, the depth of the $L_{C R}$ wave penetration is expected to be a function of frequency. However, there is no definite relation between $L_{C R}$ depth and frequency. Hence, the $L_{C R}$ depth should be measured experimentally. A variable depth groove is cut in a pipe, with the same material and thickness of the pressure vessel, to produce a barrier to physically prevent the $L_{C R}$ wave from reaching the receiver transducer. It was found that a $1 \mathrm{~mm}$ depth groove could completely prevent a $5 \mathrm{MHz} L_{C R}$ wave to pass, which indicates that the penetration depth of such a $L_{C R}$ wave is $1 \mathrm{~mm}$.

\section{3-4. Acoustoelastic constant evaluation}

To evaluate the acoustoelastic constant ( $L$ ), the pressure vessel is hydro tested according to the setup shown in Fig. 4. A thermal stress relieving is performed and then the value $t_{0}$ is measured directly on the parent material (PM), melted zone (MZ) and heat affected zone (HAZ) of the main and caps weld. Metallographic analysis of the welds (main and caps weld) is accomplished to determine dimensions of $\mathrm{MZ}, \mathrm{HAZ}$ and PM zone. The pressure vessel is filled with the water and the internal pressure is increased step by step via a hydraulic hand pump. The stress on the outer surface is calculated according to the ASME-Sec.-VIII while, two strain gauges are employed to verify the calculations. The measurement process includes holding in a certain pressure; moving the TOF measuring element on the PM, HAZ and MZ; measuring the TOF on different zones and measuring the strain by the strain gauges. All the procedures are repeated for 8 different internal pressures by axial and hoop wedge. The acoustoelastic constant $(L)$ of the PM, HAZ and MZ is then calculated based on Eq. (1). However, the HAZ constant measurement is impractical in the axial direction because of dimensional limitations.

The acoustoelastic constant can be also evaluated by a tensile test on the specimens extracted from the PM and MZ. Inducing machining stresses during the extracting tensile test specimens is a practical limitation of constant measurement through the tensile test method. The other limitation is extracting the specimen from the HAZ because of dimensional difficulties. Furthermore, the investigated sample should be destroyed to extract the tensile test specimens. However, measurement of the acoustoelastic constant through the hydro test is a unique advantage of pressure vessels. It is possible to present a uniform distribution of acoustoelastic constant in the entire of the pressure vessel while the investigated sample is kept intact.

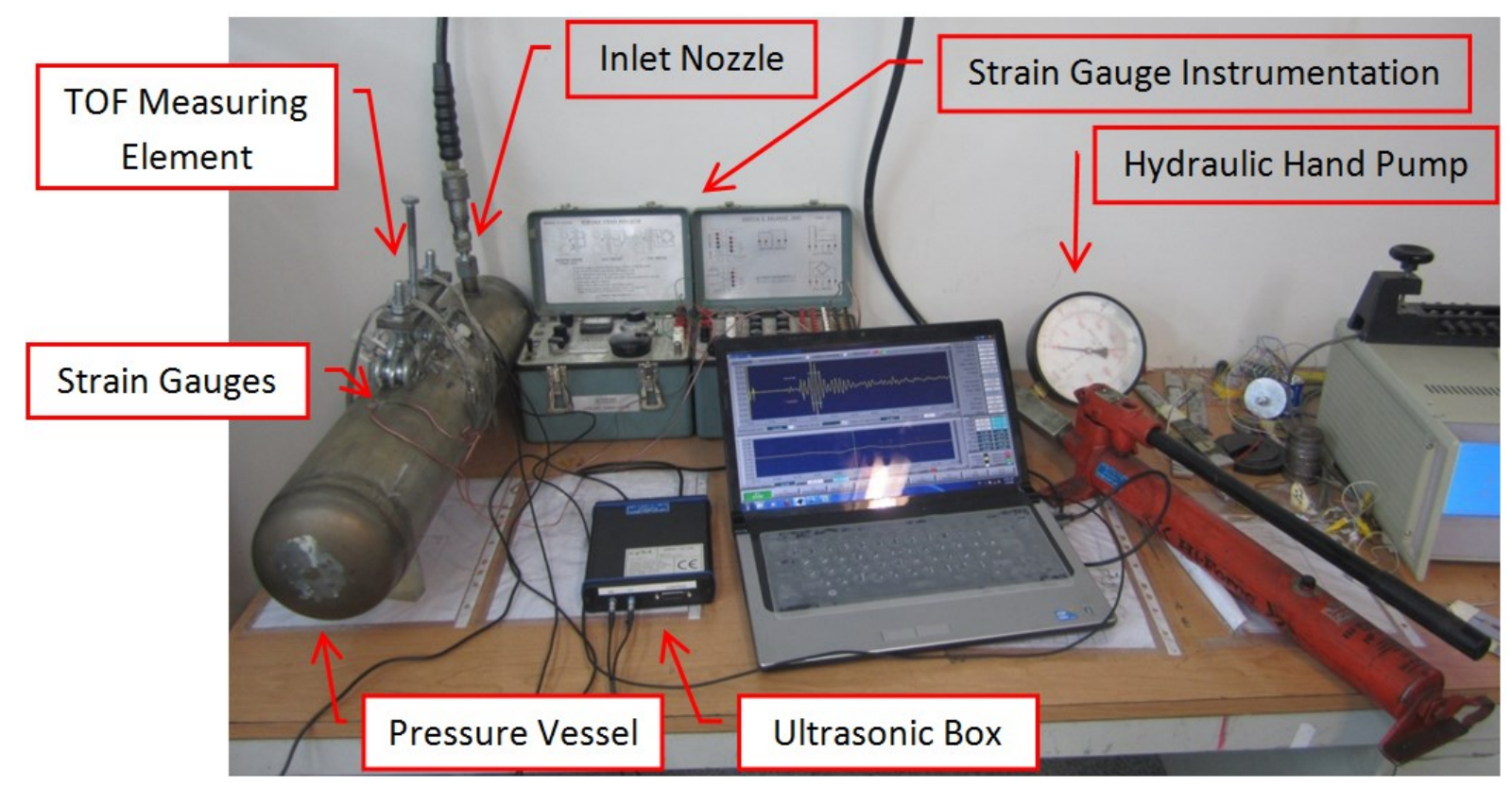

Fig. 4. Hydro test setup to measure acoustoelastic constant of the pressure vessel

\section{4- RESULTS AND DISCUSSION}

The results of hydro test are shown in Fig. 5 and Fig. 6 corresponding to the hoop and axial direction respectively, where the slope of the lines represents $L$ acoustoelastic constants. The value of measured hoop acoustoelastic constant is 1.78 , 
1.86 and 2.248 in the HAZ, PM and MZ respectively which show that the HAZ constant is less than the PM whereas the maximum is the $\mathrm{MZ}$ constant. There is some difference between hoop constant with the axial constant which is measured equal to 2.09 and 2.28 in the PM and MZ respectively. However, the axial constant of the HAZ is impractical to be measured because the width of HAZ is less than $2 \mathrm{~mm}$ which is not enough to distinguish between $\mathrm{HAZ}$ and $\mathrm{MZ}$ measurements in axial direction. The elastic modulus $(E)$ mentioned in the vertical axis is measured equal to $196 \mathrm{GPa}$ and $199 \mathrm{GPa}$ through tensile test of the PM and MZ samples respectively.

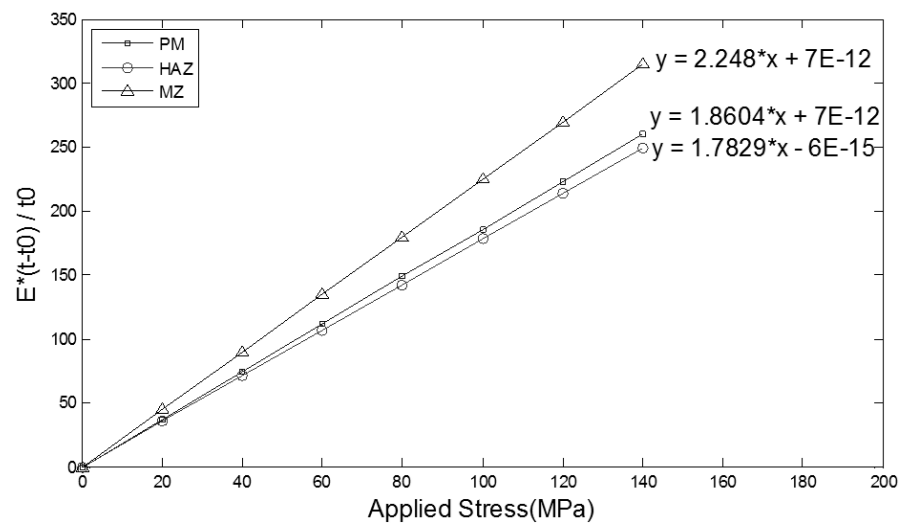

Fig. 5. Results of hydro test to evaluate hoop acoustoelastic constant

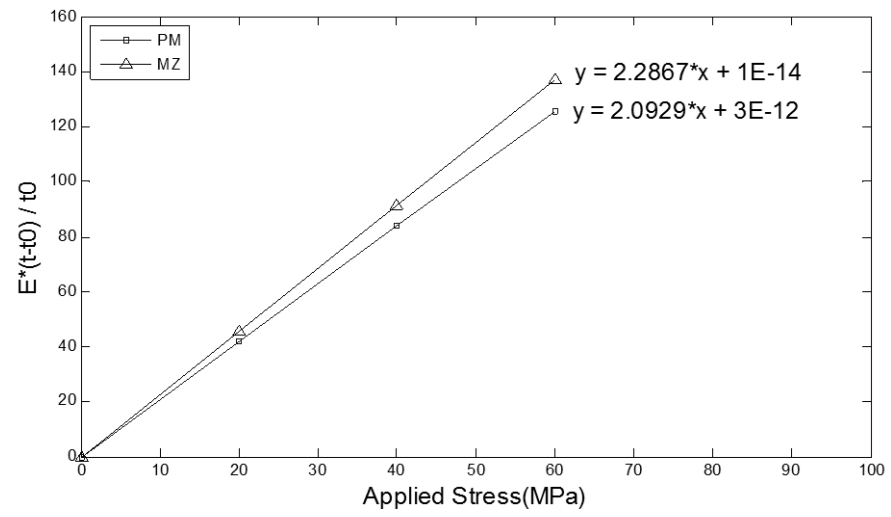

Fig. 6. Results of hydro test to evaluate the axial acoustoelastic constant

The residual stresses are measured by the ultrasonic method according to the results shown in Fig. 7 and Fig. 8 corresponding to the axial and hoop direction respectively. The results are obtained in 90 and 270 degree which represents the path 1 and path 2 respectively (Fig. 2). The hole-drilling method is also employed to verify the ultrasonic results while the 5 points are tested on the main and caps weld (according to the positions shown in the Fig. 2). Comparison of the ultrasonic and hole-drilling results shows good agreement which validate the ultrasonic measurements. 


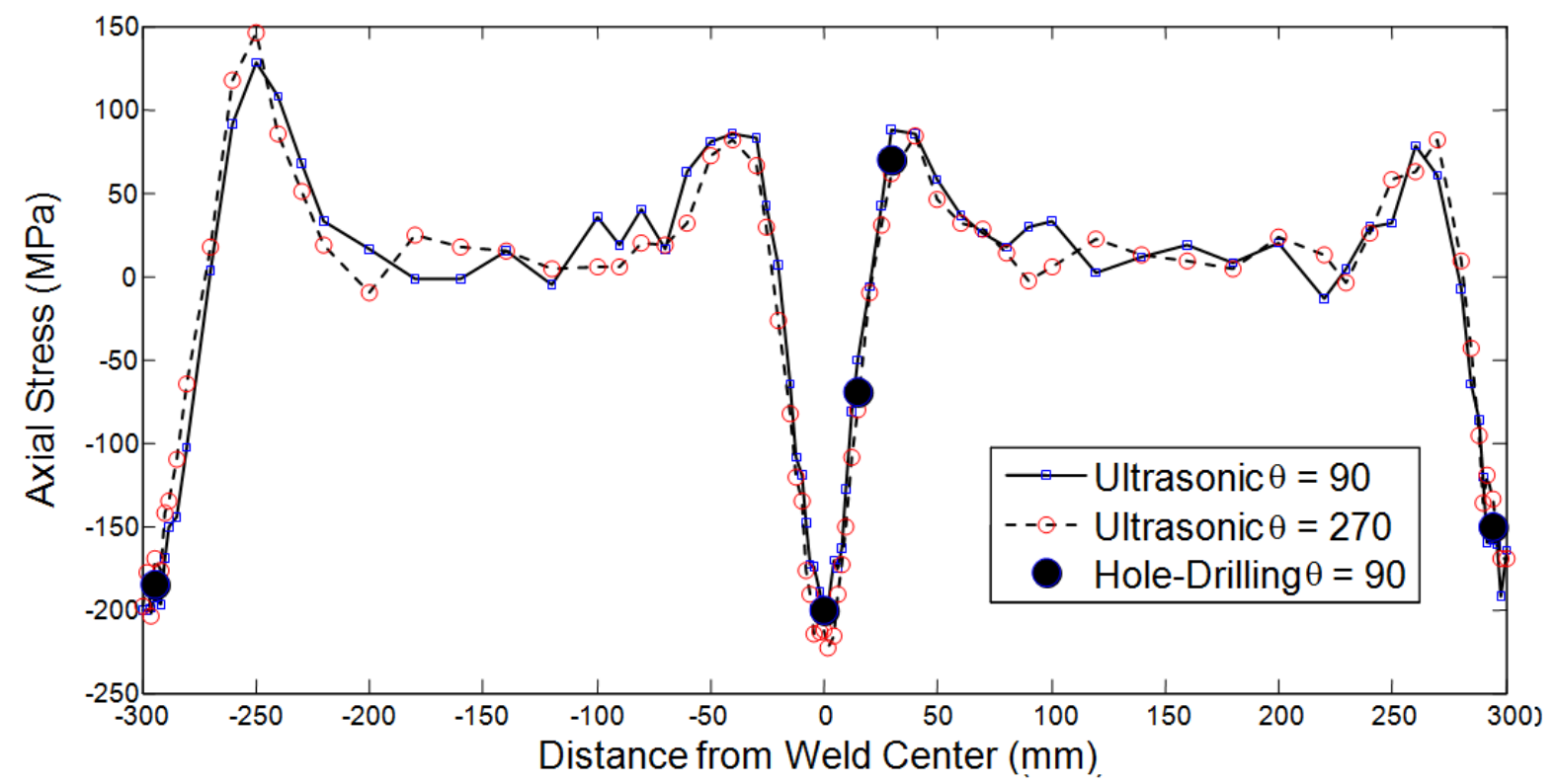

Fig. 7. Axial residual stresses of the pressure vessel measured by the ultrasonic and hole-drilling method

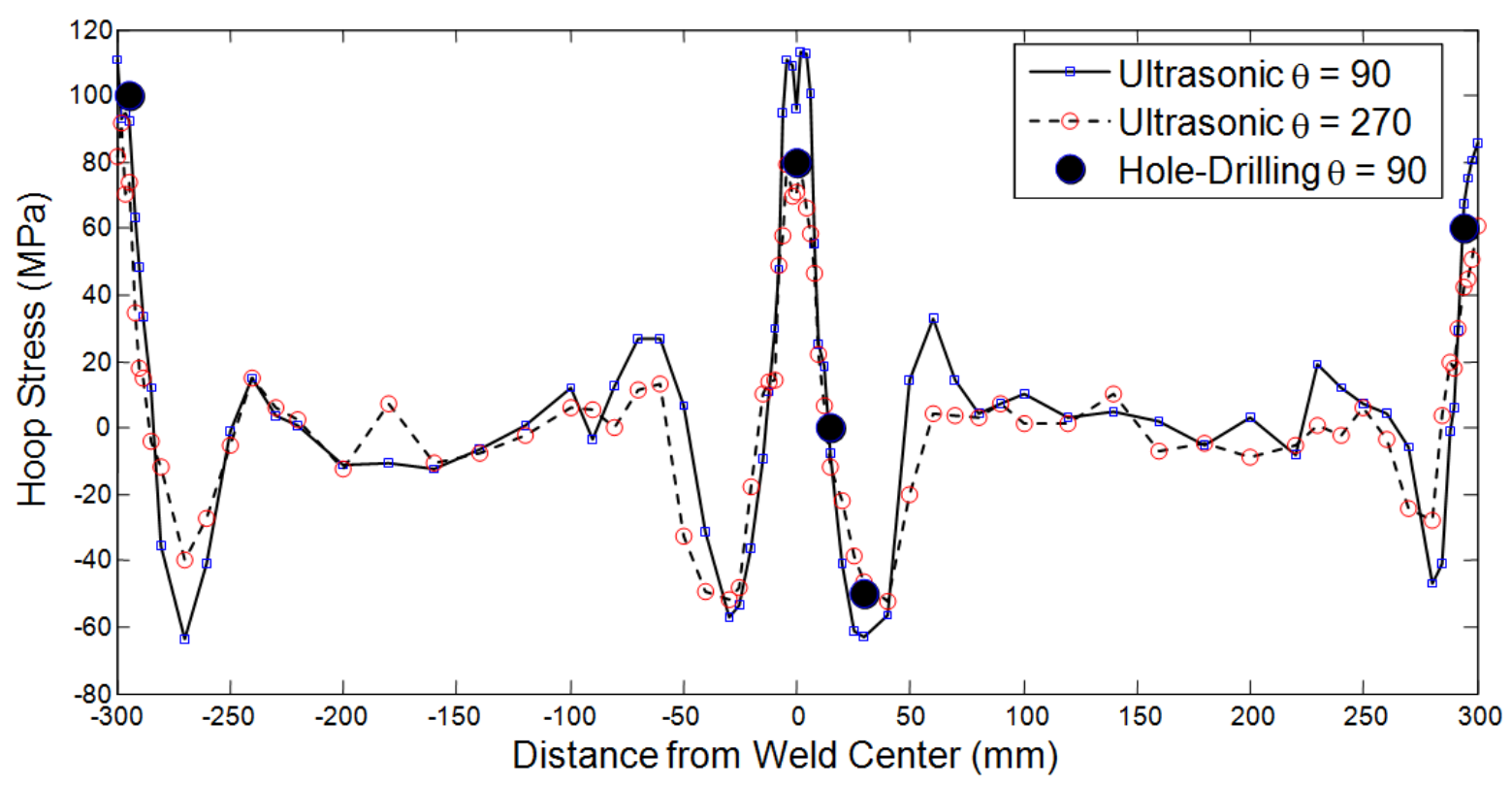

Fig. 8. Hoop residual stresses of the pressure vessel measured by the ultrasonic and hole-drilling method

The results are corresponding to the outer surface of the pressure vessel because the penetration depth of the $5 \mathrm{MHz} L_{C R}$ wave is measured $1 \mathrm{~mm}$ and also the hole-drilling is approximately a surface method. The axial residual stress is equal to $223 \mathrm{MPa}$ which is compressive stress in the main weld centerline while the hoop stress of this zone is tensile. The maximum of measured axial stress is $-205.475 \mathrm{MPa}$ and $-193.95 \mathrm{MPa}$ in the left and right cap weld respectively. The welding mechanical constraints of the left and right cap are the same; therefore the difference between the peaks of residual stress is attributed to different welding energy.

Distribution of the axial residual stress is more uniform than hoop stress which can be justified by surface distortions of the pressure vessel. The positioning of the hoop wedge is more difficult than the axial wedge because of welding deformations of tested surface.

The hoop residual stress is more influenced by the scanning path than the axial stress. It means that, difference between $90^{\circ}$ with $270^{\circ}$ results corresponding to the hoop stress results is higher than the axial stress results. 


\section{5- CONCLUSION}

The main goal of this paper is ultrasonic evaluation of hoop and axial residual stresses in a stainless steel pressure vessel. The ultrasonic measurements are also compared with residual stresses obtained from hole-drilling method. According to the achieved results, it can be concluded that:

1- The evaluation of acoustoelastic constant through the hydro test in comparison with the tensile test has some advantages which are: keeping the investigated sample intact; measuring the HAZ constant and eliminating the machining process to extract the specimens.

2- The value of measured acoustoelastic constant show that the HAZ constant is less than the PM whereas the maximum is the $\mathrm{MZ}$ constant.

3- There is some difference between hoop acoustoelastic constant with the axial constant measurement.

4- Comparison of the ultrasonic and hole-drilling results shows good agreement corresponding to the measured axial and hoop residual stresses of the pressure vessel.

5- The axial residual stress is compressive in the weld centerline while the hoop stress is tensile.

6- The residual stress of the left cap weld is higher than that obtained from the right cap weld because of higher welding energy in the left cap welding process.

7- Distribution of the axial residual stress is more uniform than hoop stress which can be justified by surface distortions of the pressure vessel.

8- The hoop residual stress is more influenced by the scanning path than the axial stress.

\section{6- REFERENCES}

[1] Thompson, R. B., Lu, W. Y., and Clark Jr., A. V., 1996, Handbook of Measurement of Residual Stress, eds., J. Lu, M. James, and G. Roy, Society for Experimental Stress Analysis, Bethel, Connecticut, Chap. 7, pp. 149-178.

[2] Schneider, E., 1997, Structural and Residual Stress Analysis by Nondestructive Methods, ed. V. Hauk, Elsevier, Amsterdam, Chap. 4, pp. 522-563.

[3] Santos, A., and Bray, Don E., 2000, "Ultrasonic Stress Measurement Using PC Based and Commercial Flaw Detectors," Rev. Sci. Instrum., 71(9), pp. 3464-3469.

[4] Santos, A. A., and Bray, Don E., 2000, "Application of Longitudinal Critically Refracted Waves to Evaluate Stresses in Railroad Wheels," Topics on Nondestructive Testing, Vol. 5, The American Society for Nondestructive Testing.

[5] Bray, D. E., and Chance, B., 1999, "Practical Aspects of Ultrasonic Stress Measurement," ed. C. Darvennes, ASME NDE-Vol. 19, pp. 75-79.

[6] Tanala, E., Bourse, G., Fremoit, M., and De Belleval, J. F., 1995, "Determination of Near Surface Residual Stresses on Welded Joints Using Ultrasonic Methods," NDT \& E Int., 28(2), pp. 83-88.

[7] Szelazek, J., 1998, "Monitoring of Thermal Stresses in Continuously Welded Rails with Ultrasonic Technique," ECNDT '98, Copenhagen 26-29 May, Vol. 3, No. 6, NDT Net, June.

[8] Bray, D. E., 2002, "Ultrasonic Stress Measurement and Material Characterization in Pressure Vessels, Piping, and Welds", J Press Vess, 124, pp. 326-335.

[9] Egle, D. M. and Bray, D. E., 1976, "Measurement of Acoustoelastic and Third-Order Elastic Constants for Rail Steel”, J Acoust Soc Am, 60(3), pp. 741-744. 


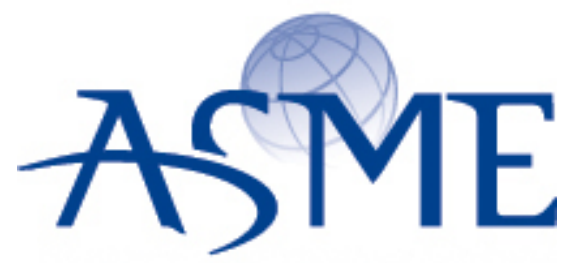

\section{American Society of Mechanical Engineers}

SETTING THE STANDARD

\section{ASME Accepted Manuscript Repository}

\section{Institutional Repository Cover Sheet}

ASME Paper Title: Ultrasonic evaluation of welding residual stresses in stainless steel pressure vessel

Authors:

Javadi, Y., Pirzaman, H. S., Raeisi, M. H., \& Najafabadi, M. A

ASME Journal Title: Journal of Pressure Vessel Technology, Transactions of the ASME

Volume/Issue $135 / 4$ Date of Publication (VOR* Online) _ 11/6/2013

https://asmedigitalcollection.asme.org/pressurevesseltech/articleabstract/135/4/041502/379076/Ultrasonic-Evaluation-of-Welding-ResidualASME Digital Collection URL: Stresses?redirectedFrom=fulltext

DOI:

ASME C

*VOR (version of record) 